\title{
Which one is more effective for the treatment of rat sepsis model: thalidomide or etanercept?
}

\author{
Ilhan $\mathrm{N}^{1}$, Susam $\mathrm{S}^{1}$, Gul $\mathrm{HF}^{1}$, Bardas $\mathrm{R}^{2}$, Ilhan $\mathrm{N}^{1}$ \\ Firat University, Faculty of Medicine, Department of Medical Biochemistry, Elazig, Turkey. \\ drnilhan@yahoo.com
}

\begin{abstract}
OBJECTIVE: We aimed to investigate the protective effect of selected treatment agents on liver injury in lipopolysaccharide (LPS)-induced rat sepsis model.

BACKGROUND: The sepsis includes complex inflammatory responses between a microbial pathogen and the host immune system, and leads to organ failure and also death.

METHODS: This study was performed with 29 male Wistar Albino rats. Rats were divided randomly into five groups: Sham group, LPS-treated sepsis group, LPS+thalidomide treated group, LPS+etanercept treated group and LPS+thalidomide+etanercept treated group, respectively. Liver tissue tumor necrosis factor $\alpha$ (TNF- $\alpha)$, interleukin $1 \beta(\mathrm{IL}-1 \beta)$ and interleukin 6 (IL-6) levels were determined by enzyme-linked immuno-sorbent assay (ELISA) method. The expression of nuclear factor kappa-light-chain-enhancer of activated B cells (NF-KB) was performed using western blot analysis.

RESULTS: The levels of tissue TNF- $\alpha$, IL-1 $\beta$ and IL- 6 were found statistically significantly higher in sepsis group than in the sham group. TNF- $\alpha$ levels were found statistically significantly decreased in LPS+etanercept and LPS+thalidomide+etanercept treated groups when compared with LPS group $(p<0.05)$. For IL-1 $\beta$ and IL-6 levels a statistically significant decline was observed in the LPS+thalidomide and LPS+etanercept treated groups compared to the LPS group $(p<0.05)$. Expression of NF-KB protein in liver tissue was significantly elevated in the LPS group compared to sham group $(p<0.001)$. In treatment groups, a marked decrease was observed in NF-kB protein expression. CONLUSION: The results of this investigation suggested that etanercept and thalidomide administration may have a beneficial effect on LPS-induced sepsis. So, the present study may have significant clinical relevance, but clinical trials are needed to confirm these results (Tab. 1, Fig. 1, Ref. 36). Text in PDF www.elis.sk. KEY WORDS: sepsis, IL-1 $\beta$, IL-6, TNF- $\alpha$, treatment agents.
\end{abstract}

\section{Introduction}

Sepsis, a form of systemic inflammatory response syndrome (SIRS), is a result of pathogen or conditional pathogenic bacteria invasion into the blood circulation (1). The predominant microorganisms that cause sepsis are gram-negative bacteria. Lipopolysaccharide (LPS), the main component of the cell wall of gram-negative bacteria, causes uncontrolled inflammatory response, organ failure and even death (2). During inflammation, LPS progresses to gradually act on a lot of host cells, primarily monocytes and macrophages, triggering a number of proinflammatory cytokines such as tumor necrosis factor alfa (TNF- $\alpha$ ), interleukin $1 \beta$ (IL-1 $\beta$ ) and interleukin-6 (IL-6) in sepsis $(3,4)$. The overproduction of inflammatory cytokines causes SIRS, which is the main reason of death in septic patients, and they cause a series of cellular-level alterations in the vascular and immune systems as well as in the

${ }^{1}$ Firat University, Faculty of Medicine, Department of Medical Biochemistry, Elazig, Turkey, and ${ }^{2}$ Firat University, Faculty of Medicine, Department of Child Health and Disease, Elazig, Turkey

Address for correspondence: $\mathrm{N}$. Ilhan, MD, PhD, Firat University, Medical Faculty, Department of Medical Biochemistry, 23119, Elazig, Turkey. Phoen: +90.424.2370000, Fax: 0424212271 remaining tissues, directly or indirectly $(2,3)$. TNF- $\alpha$ has a significant role in the development of organ dysfunction due to sepsis. It induces organ damage through activation of endothelial cells and neutrophils, and additionally, coagulation abnormalities in patients with sepsis. In the light of this knowledge, TNF- $\alpha$ inhibition might prove to be crucial in treating septic organ dysfunction $(5,6)$.

Secretion of cytokines like IL-1 $\beta$ and IL- 6 may also be induced by TNF- $\alpha$ (7). It is acknowledged that IL- $1 \beta$ and TNF- $\alpha$ has biological and functional similarities (8). They cause more severe clinical signs by acting in synergy. High IL-1 $\beta$ levels are detected in patients with sepsis. IL-1 $\beta$ secretion also results in symptoms such as fever, anorexia, sepsis and hypotension $(9,10)$.

As another cytokine secreted in sepsis, IL-6 is released by macrophages and $\mathrm{T}$ cells to induce immune response occurring during infection and after trauma, especially burns or other tissue damage leading to inflammation (11). The role of IL-6 levels in sepsis and SIRS is a matter of controversy (12), since high levels may also be defined after trauma, surgical operation, or in autoimmune disease patients. Nevertheless, IL-6 expression and sepsis severity are correlated (13).

Nuclear factor kappa B (NF- $\mathrm{B})$ is the final target of agents that induce septic shock. NF- $\kappa \mathrm{B}$ participates in or controls the transcription of more than 200 genes that take part in the selec- 
tion of physiological and pathophysiological processes, particularly regarding immunity and inflammation. NF- $\kappa \mathrm{B}$ activation is a central molecular occurrence leading to pathogenesis of organ injury and lethality during sepsis. In in vivo models, both LPS and bacteria challenge have been shown to increase NF- $\kappa B$ activation in a variety of different tissues and organs. NF- $\kappa B$ activity is also perceptibly increased in septic shock patients, while the degree of NF- $\kappa \mathrm{B}$ activity and the severity of the disease are correlated. Higher NF- $\mathrm{KB}$ activity is linked to higher rates of mortality and worse clinical outcome. Transcriptional expression of several proinflammatory genes playing important part in the pathophysiology of sepsis is mediated by activation of NF- $\mathrm{BB}(14,15)$.

Despite the improved outcome of sepsis due to the increased and early use of antibiotics, corticosteroids, and supportive care, the incidence of severe sepsis is still increasing. Currently, there are no clinically specific therapeutic agents. Controlling the pathological effects of excess IL- $1 \beta$, IL- 6 , TNF- $\alpha$ and NF- $\kappa$ B production is important for sepsis therapy; in vitro and in vivo experiments employ a large number of therapeutic agents. One of these is thalidomide, which has been demonstrated to suppress production of TNF- $\alpha$ by human monocytes in vitro $(12,13)$ and to stabilize elevated serum levels of TNF- $\alpha$ in vivo. The main influence of thalidomide is the selective down-regulation of TNF- $\alpha$ production by monocytes' activation. However, comparable inhibiting effects have also been reported for IL-6 and, to a smaller extent, in production of interferon-gamma (IFN- $\gamma$ ). Another therapeutic agent is etanercept, which is a fusion protein formed by recombinant DNA. It binds specifically to TNF- $\alpha$ and blocks its communication with TNF- $\alpha$ receptors on the cell surface. Etanercept's inhibition of TNF- $\alpha$ decreases inflammatory response and this is particularly useful in the treatment of autoimmune diseases (16).

In order to further explore the potential applicability of therapeutic NF- $\mathrm{KB}$ inhibition in sepsis and to investigate the variables that might alter the effectiveness of this approach, we have provided two agents separately and together as treatment agents in the novel study. Also, we aimed to investigate the protective role of selected treatment agents on liver injury, NF- $\mathrm{kB}$ expression and sepsis-related proinflammatory cytokines in LPS-induced rat sepsis model, because the animal models that accurately mimic human disease are extremely valuable as they speed up the development of clinically useful therapeutics.

\section{Materials and methods}

\section{Animals}

This study comprised of 29 male, one-week-old Wistar Albino rats (body weight, $10.3 \pm 2.4 \mathrm{~g}$ ). All animals were housed at the Firat University Experimental Animal Center (Elazig, Turkey) in a controlled environment (12:12 h light/dark cycle with a temperature of $22 \pm 2{ }^{\circ} \mathrm{C}$ and a relative humidity of $50-60 \%$ ). All groups were given standard rat chow and the daily care for the animals was performed. All experimental procedures were approved by the Clinical Ethics Committee and the Animal Care Committee of Firat University (Number of Meetings: 17, Decision No: 156). The rats were randomly divided into five groups: sham and endotoxic groups. Sham group' rats $(n=10)$ were given $1 \mathrm{~mL}$ intraperitoneal (i.p.) injection of $0.9 \%$ saline solution. For endotoxic treatment, rats were divided into four groups injected intraperitoneally with LPS (Escherichia coli 0111:B4, 5 mg. $\mathrm{kg}^{-1}$ body weight, a single dose), LPS+thalidomide (ED50 for rats, 0.5 $\mathrm{mg} \cdot \mathrm{kg}^{-1}$ body weight), LPS+etanercept (ED50 for rats, $1 \mathrm{mg} \cdot \mathrm{kg}^{-1}$ body weight) and LPS+thalidomide+etanercept. The volume of each dose administered was $4 \mathrm{ml} . \mathrm{kg}^{-1}$ body weight. Treatment agents were administered to rats taking into account therapeutic anti-inflammatory doses (ED50) and half an hour later LPS injection. All injections were prepared fresh on the treatment day.

Animals were sacrificed $24 \mathrm{~h}$ after LPS-challenge to obtain liver tissue. And still all animals received humane care, and all study protocols were approved by the institutional animal care and use committee.

\section{Preparation of tissue homogenates}

After being blotted dry on filter papers, the tissues were weighed and homogenized in 0.1 M PBS using automatic tissue homogenizer (Ultra TurraxType T25-B, IKA Labortechnic, Germany) at 3,000 rpm for $10 \mathrm{~min}$ at $4{ }^{\circ} \mathrm{C}$. Samples were clarified by two rounds of centrifugation at $6000 \mathrm{~g}$ for $20 \mathrm{~min}$ at $4{ }^{\circ} \mathrm{C}$. The resulting supernatants were collected and stored at $-80{ }^{\circ} \mathrm{C}$ for assays. TNF- $\alpha$, IL- $1 \beta$ and IL- 6 levels in liver supernatant were determined by rat enzyme-linked immunosorbent assay (ELISA) kits (Sunred Biological Techonogy/Shanghai, China) according to manufacturer's recommendations. The optical density of each well was measured at $450 \mathrm{~nm}$ using an ELX 800 ELISA reader. The concentrations were calculated based on standard curves.

\section{Western blot analysis of NF-kB}

Excised, the frozen liver tissues were weighed and homogenized with RIPA lysis buffer with Cocktail protease inhibitor utilizing an automatic tissue homogenizer (Ultra TurraxType T25-B, IKA Labortechnic, Germany). All procedures were performed at $4{ }^{\circ} \mathrm{C}$; according to the manufacturer's instructions. Homogenized samples were centrifuged at $10.000 \times \mathrm{g}$ for 10 minutes to acquire the supernatant and then recentrifuged to form a clear lysate. Samples were stored at $-80{ }^{\circ} \mathrm{C}$ until analysis. The amount of protein in the samples was determined with a Qubit fluorometer using a Quant$\mathrm{iT}^{\mathrm{TM}}$ protein kit. Fifty micrograms of the total protein were loaded on gels (NuPAGE 4-12\% Bis-Tri; Invitrogen) for electrophoresis, transferred to a polyvinylidene fluoride (PVDF) membrane, and probed with rabbit polyclonal antibody against polyclonal rabbit NF-кB-p105 (1:500 1:1000, obtained from arigo. biolaboratories, Taiwan, Republic ofChina). After the membranes were washed with Tris-buffered saline-Tween (TBST), incubated with a horseradish peroxidase-conjugated secondary antibody, the bands were exposed using an enhanced chromogenic kit (Western Breeze Chromogenic Immunodetection Kit; Invitrogen). After development protein bands were visualized with Image-pro Plus 6.0 analysis software.

\section{Statistical analysis}

All statistical analyzes were performed with SPSS 22.0 statistical software package (IBM, Armonk, NY, USA) for this pur- 
Tab. 1. The levels of tissue TNF- $\alpha$, IL-1 $\beta$ and IL-6 for all groups.

\begin{tabular}{|c|c|c|c|}
\hline Group & TNF- $\alpha$ (ng/100 mg wet tissue) & IL-1 $\beta$ (pg/100 mg wet tissue) & IL-6 (pg/100 mg wet tissue) \\
\hline Sham & $148.944 \pm 14.45$ & $913.888 \pm 251.31$ & $77.462 \pm 15.23$ \\
\hline LPS & $267.311 \pm 98.15^{\mathrm{a}}$ & $1485.204 \pm 207.25^{\mathrm{a}}$ & $139.143 \pm 13.34^{\mathrm{a}}$ \\
\hline LPS+Thalidomide & $187.970 \pm 85.71$ & $978.870 \pm 534.18^{\mathrm{b}}$ & $80.509 \pm 16.39^{c}$ \\
\hline LPS+Etanercept & $160.207 \pm 24.85^{\mathrm{b}}$ & $905.191 \pm 446.83^{b}$ & $98.739 \pm 23.39^{\mathrm{b}}$ \\
\hline LPS+Thalidomide+Etanercept & $143.204 \pm 78.37^{\mathrm{b}}$ & $1139.661 \pm 330.97$ & $107.974 \pm 44.46$ \\
\hline
\end{tabular}

pose. A value of $\mathrm{p}<0.05$ was considered to be significant. Comparisons between different groups were performed using the one way analysis of variance (ANOVA). Differences were considered significant at probability levels of $\mathrm{p}<0.05$ with the Tukey HSD method. The results are presented as mean \pm standard deviation of the mean (SD).

\section{Results}

The levels of tissue TNF- $\alpha$, IL- $1 \beta$ and IL- 6 for all groups were presented in Table 1 as mean \pm SD. All cytokines levels were found to be higher in the LPS-treated group with respect to the sham group.

As a proinflammatory cytokine, TNF- $\alpha$ levels were examined because they have an important role in pathogenesis of sepsis. LPS stimulated TNF- $\alpha$ production and a high amount of the cytokine was measured in liver tissue of the rats injected with LPS. Compared with the level of TNF- $\alpha$ in the sham group (148.944 \pm 14.45 $\mathrm{ng} / 100 \mathrm{mg}$ wet tissue), LPS profoundly increased (267.311 \pm 98.15 $\mathrm{ng} / 100 \mathrm{mg}$ wet tissue; $\mathrm{p}<0.005)$ in liver tissue. The group treated with etanercept displayed a significant $(160.207 \pm 24.85 \mathrm{ng} / 100$ mg wet tissue; $\mathrm{p}<0.005$ ) reduction of TNF- $\alpha$ compared with LPS group. Co-administration of thalidomide with LPS+etanercept made the suppressive effect of etanercept on TNF- $\alpha$ even more pronounced (143.204 $\pm 78.37 \mathrm{ng} / 100 \mathrm{mg}$ wet tissue).

It was known that TNF- $\alpha$ and IL- $1 \beta$ lead to more severe clinical signs by acting synergistically, so tissue IL- $1 \beta$ levels in the LPS group were markedly increased when compared to sham group. The IL-1 $\beta$ levels were significantly reduced upon etanercept and also thalidomide treatment in comparison with LPS group $(\mathrm{p}<$ $0.05)$. Co-administration of thalidomide+etanercept did not support the lowering action of only etanercept or only thalidomide treatment on LPS-induced IL-1 B levels in liver tissue, the effect was not significant.

During inflammation, LPS triggers releasing of IL-6. Hence, it was determined that tissue IL-6 levels after LPS injection were significantly increased in LPS group relative to sham group $(\mathrm{p}<0.05)$. After treatment with etanercept or thalidomide, IL-6 levels were significantly lower in LPS+etanercept and also LPS+thalidomide compared to LPS group $(\mathrm{p}<0.05)$. There was also a reduction in LPS+thalidomide+etanercept group, but it wasn't statistically significant $(\mathrm{p}>0.05)$

Finally, the findings obtained from the Western blot analysis (Fig. 1), the expression of NF- $\mathrm{kB}$ protein in liver tissue was found higher in LPS-treated group with respect to the sham group $(p<0.001)$. It was found that co-administration of thalidomide and thalidomide+etanercept supported the decreasing effect on
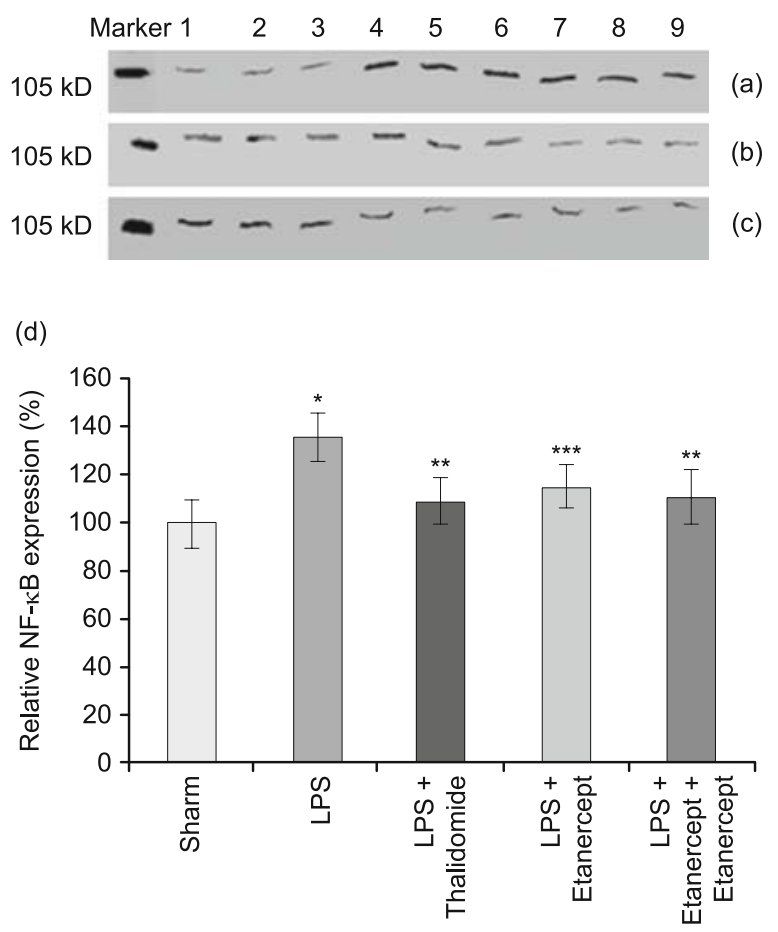

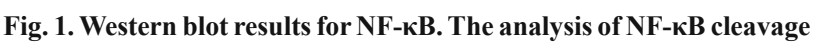
showing the effect of lipopolysaccharide (LPS) and co-administered thalidomide, etanercept and thalidomide+etanercept on NFкB protein expression. a) Lanes 1-3: sham band pattern, lanes 4-9: LPS group. b) Lanes 1-6: only etanercept-treated group and last 3 lanes: thalidomide+etanercept-treated group. c) Lanes 1-3: thalidomide+etanercept-treated group, Lanes 4-9: only thalidomidetreated group. Marker: Molecular weights of the protein bands in the SeeBlue ${ }^{\circledast}$ Plus2Pre-Stained Standard. Western blotting was normalized to actin expression and expressed relative to the control sample. The corresponding densitometric analysis is also shown (d). Data are means \pm SD of three independent experiments. $* \mathbf{p}<0.001$, compared with the sham group; $* * \mathrm{p}=0.001$ and ${ }^{* * *} \mathrm{p}<0.05$, compared with LPS alone (Tukey HSD).

expression levels of NF- $\kappa \mathrm{B}$ with respect to LPS alone group ( $\mathrm{p}$ $=0.001$, for both groups), and also this reduction was showed in etanercept-treated group $(\mathrm{p}<0.005)$.

\section{Discussion}

Data obtained from the novel experimental study demonstrated that the severity of proinflammatory immune system response after infection will facilitate organ damage or increase the existing injury. Therefore, efforts to treat inflammatory response may provide 
advantages for opening new horizons in the treatment of sepsis and reducing it. In recent decades, it has been seen that several mediators of inflammation tend to get higher during sepsis. The concentrations of some proinflammatory cytokines in systemic circulation, especially of IL- 6 and TNF- $\alpha$, were reported to rise in severe infections and septic shock (16).

TNF- $\alpha$, a primary mediator of inflammation, has been linked to various infectious and non-infectious inflammatory diseases (17). In human and animal sepsis models induced by injection of bacterial endotoxin, TNF- $\alpha$ production is activated quickly, and this can be detected in plasma. Michiea et al, injected Escherichia coli endotoxin to healthy volunteers and observed that concentrations of TNF- $\alpha$ rose significantly and they were on peak $1 \mathrm{~h}$ after the infusion (18). The plasma of many patients with sepsis may show TNF- $\alpha$, and concentrations are usually correlated with severity of illness, as well as outcome. Endo et al (19) showed that plasma concentrations of IL-1, IL-6, TNF- $\alpha$ and interleukin 2 (IL2 ) were higher in patients with septic shock in comparison to patients with sepsis only or with other shock causes. Thus, inhibiting TNF- $\alpha$ action using therapeutic agents decreases the inflammatory response which is particularly useful in treatment of autoimmune diseases (16). For instance, Pascual et al reported TNF- $\alpha$ pathway inhibition by propolis, while Jung WK et al showed decreases in levels of TNF- $\alpha$ and IL-1 $\beta$ in the serum by CAPE treatment in lipopolysaccharide-induced septic shock model in mice $(20,21)$. Another study showed strong inhibition of LPS-induced systemic inflammatory responses known to be mediated by TNF- $\alpha$ as well as IL-6 and C-reactive protein release using etanercept, indicating effective inhibition of TNF- $\alpha$ activity by etanercept (22). Our results were consistent with the studies mentioned above. In the present study, TNF- $\alpha$ concentrations were significantly increased in the LPS-induced rats relative to the sham group. After administering thalidomide and etanercept as therapeutic agents, significant decreases were found in TNF- $\alpha$ level. Consequently, it can be said that this reduction is due to the suppressive effect of the selected treatment agents on TNF- $\alpha$.

Endotoxin-stimulated human monocytes produce IL-1 $\beta$, which is found in the plasma of septic animals (23). IL-1 $\beta$ is elevated in humans after endotoxin infusion, though in lower rates than TNF- $\alpha$ (24). In similarity to TNF- $\alpha$, IL- $1 \beta$ triggers the production of other cytokines. McAllister et al (25) reported cytokine measurements made in three patients who developed sepsis following transfusion with packed erythrocytes infested with gram-negative bacteria. These patients' detectable IL- $1 \beta$ levels were on peak by 4 $\mathrm{h}$ and they returned to normal subsequently in the two survivors, while remaining high for 22 hours in the patient who later passed away. IL-1 $\beta$ can be detected in the plasma in a small number of patients with sepsis, but it appears to be a measure of sepsis severity. We also found that the levels of IL- $1 \beta$ in tissue were higher in the LPS group than in the sham group. In addition to this, it was found that there was a significant decrease in IL-1 $\beta$ levels in the groups treated with etanercept and thalidomide alone. When the effects of selected treatment agents on IL-1 $\beta$ levels were examined, it was thought that this decrease is due to the fact that IL-1 $\beta$ has synergistic effect with TNF- $\alpha$.
IL-6 has a diversity of biological effects, comprising induction of acute phase protein production in the liver, activation of B- and T-lymphocytes, and modulation of hematopoiesis (26). IL-6 infusion into animals used in experiments does not result in a condition like sepsis (27). Martin et al reported that levels of TNF- $\alpha$, IL- 6 and IL- 8 in the serum were higher in newborns who were septic as opposed to newborns who were not (28). Shin et al (29) consistently observed systemic inflammatory responses such as higher concentrations of proinflammatory cytokines TNF- $\alpha$ and IL-6 with LPS, in comparison to control rats. Yanay et al found significantly higher levels of TNF- $\alpha$, IL- 6 and IL- $1 \beta$ in the LPS group than the sham group (30). Our study obtained similar results. Liver tissue levels of IL-6 were significantly increased in LPS-induced rats compared to sham group and treatment groups in the present study. Our results showed that up-regulation of TNF- $\alpha$ resulted in activated and increased IL- 6 level. Considering that increased cytokines levels were associated with sepsis pathogenesis

Inflammatory cytokine induction in immune cells by LPS has been reported to happen through the signal transduction pathway mediated by NF-kB (31). NF-kB is a prevalent factor of transcription which takes part in the regulation of numerous inflammatory genes' expression. During NF-kB activation, this transcription factor's translocation from the cytoplasm to nuclei is very influential for the regulation of certain pro-inflammatory genes' expression. Animal model studies on septic shock stimulated either by cecal ligation and puncture (CLP, polymicrobial model) or by LPS (endotoxin model) have shown that NF-kB inhibitors with diverse chemical properties and action mechanisms protect animals from septic fatality $(32,33)$. Molecules shown to defend mice from lethal endotoxemia (34) or to enhance survival in patients with severe sepsis (35) employ their protective effect via inhibition of NF-kB activation. In our study, higher NF-kB expression was found in the LPS group than the sham group. It was observed that all groups treated with treatment agents showed a significant decrease in expression levels of NF- $\mathrm{kB}$ in comparison to LPS alone group. Thus, blocking the initial nuclear translocation of NF-kB was able to prevent sepsis development (36). However, modulation rather than blocking of NF-kB activation is likely to be the most effective way for improving the outcome of sepsis, as intact inflammatory response is essential in maintaining host defense mechanisms normal.

Consequently, our results demonstrated that both etanercept and thalidomide administration may have beneficial effects on sepsis induced by LPS. As a treatment option, etanercept in combination with thalidomide was also considered to be effective against sepsis.

\section{References}

1. Wu J, Hu L, Zhang G, Wu F, He T. Accuracy of Presepsin in Sepsis Diagnosis: A Systematic Review and Meta-Analysis. PLoS One 2015; 10 (7): $\mathrm{e} 0133057$.

2. Qin $X$, Jiang $X$, Jiang $X$ et al. Micheliolide inhibits LPS-induced inflammatory response and protects mice from LPS challenge. Sci Rep 2016; 17 (6): 23240. 
3. Lo'pez-Bojo'rquez LN, Dehesa AZ, Reyes-Tera'n G. Molecular Mechanisms, Involved in the Pathogenesis of Septic Shock. Arch Med Res 2004; 35 (6): 465-479.

4. Fantuzzi L, Puddu P, Varano B, Del Corno M, Belardelli F, Gessani S. IFN-alpha and IL-18 exert opposite regulatory effects on the IL-12 receptor expression and IL-12-induced IFN-gamma production in mouse macrophages: novel pathways in the regulation of the inflammatory response of macrophages. J Leukoc Biol 2000; 68 (5): 707-714.

5. Iba T, Miyasho T. Danaparoid sodium attenuates the increase in inflammatory cytokines and preserves organ function in endotoxemic rats. Crit Care 2008; 12 (4): R86.

6. Ren Y, Xie Y, Jiang G et al. Apoptotic cells protect mice against lipopolysaccharide-induced shock. J Immunol 2008; 180 (7): 4978-4985.

7. Vincent JL, Opal SM, Marshall JC, Tracey KJ. Sepsis definitions: time for change. Lancet 2013; 381: 774-775.

8. Syu-ichi K, Shouji A, Tomizawa A et al. Inhibitory effect of naringin on lipopolysaccharide (LPS)-induced endotoxin shock in mice and nitric oxide production in RAW 264.7 macrophages. Life Sci 2006; 78 (7): 673-681.

9. Reyes CS, Munoz FG, Reyes D, Gonzales G, Dominquez C et al. Role of cytokines (interleukin- $1 \beta, 6,8$, tumor necrosis factor- $\alpha$, and soluble receptor of interleukin-2) and C-reactive protein in the diagnosis of neonatal sepsis. Acta Paediatr 2003; 92: 221-227.

10. Karabacak A, Yazar E. Current approaches in the treatment of septic shock. Eurasian J Vet Sci 2006; 22 (1-2): 95-103.

11. Vincent JL, Opal SM, Marshall JC, Tracey KJ. Sepsis definitions: time for change. Lancet 2013; 381: 774-775.

12. Tsalik EL, Jaggers LB, Glickman SW et al. Discriminative value of inflammatory biomarkers for suspected sepsis. J Emerg Med 2012; 43: $97-106$.

13. Lichtenstern C, Brenner T, Bardenheuer HJ, Weigand MA. Predictors of survival in sepsis: what is the best inflammatory marker to measure? Curr Opin Infect Dis 2012; 25: 328-336.

14. Liu SF, Malik AB. NF-kB activation as a pathological mechanism of septic shock and inflammation. Am J Physiol Lung Cell Mol Physiol 2006; 290 (4): L622-L645.

15. Li X, Su J, Cui X, Li Y, Barochia A, Eichacker PQ. Can we predict the effects of NF-kappaB inhibition in sepsis? Studies with parthenolide and ethyl pyruvate. Expert Opin Investig Drugs 2009; 18 (8): 1047-1060.

16. Braun J, McHugh N, Singh A, Wajdula JS, Sato R. Improvement in patient-reported outcomes for patients with ankylosing spondylitis treated with etanercept $50 \mathrm{mg}$ once-weekly and $25 \mathrm{mg}$ twice-weekly. Rheumatology (Oxford) 2007; 46(6): 999-1004.

17. Strieter RM, Kunkel SL, Bone RC. Role of tumour necrosis factoralpha in disease states and inflammation. Crit Care Med 1993; 21: 447-463.

18. Michie HR, Manogue KR, Spriggs DR et al. Detection of circulating tumour necrosis factor after endotoxin administration. New Engl J Med 1988; 318: 1481-1485.

19. Endo $S$, Inada $K$, Inoue $Y$ et al. Two types of septic shock classifiedby the plasma level of cytokines and endotoxin. Circulat Shock 1992; 38 (4): 264-274.
20. Gonzalez PR, Torricella RG. Scavenging action of propolis extract against oxygen radicals. J Ethnopharmacol 1994; 41 (1-2): 9-13.

21. Jung WK, Choi I, Lee DY et al. Caffeic acid phenethyl ester protects mice from lethal endotoxin shock and inhibits lipopolysaccharide-induced cyclooxygenase-2 and inducible nitric oxide synthase expression in RAW 264.7 macrophages via the $\mathrm{p} 38 / \mathrm{ERK}$ and NF- $\mathrm{kB}$ pathways. Int J Biochem Cell Biol 2008; 40 (11): 2572-2582.

22. Scicluna BP, van't Veer C, Nieuwdorp M, Felsmann K, Wlotzka B, Stroes ES, van der Poll T. Role of Tumor Necrosis Factor- $\alpha$ in the Human Systemic Endotoxin-Induced Transcriptome. PLoS One 2013; 8 (11): e79051.

23. Dinarello CA. Interleukin-1 and interleukin-1 antagonism. Blood 1991; 77: $1627-1652$.

24. Cannon JG, Tompkins RG, Gelfand JA et al. Circulating interleukin-1 and tumour necrosis factor in septic shock and experimental endotoxin fever. J Infect Dis 1990; 160: 79-84.

25. McAllister SK, Bland LA, Arduino MJ, Aguero SM, Wenger PN, Jarvis WR. Patient cytokine response in transfusion-associated sepsis. Infect Immunity 1994; 62: 2126-2128.

26. Borden EC, Chin P. Interleukin-6: a cytokine with potential diagnostic and therapeutic roles. J Lab Clin Med 1994; 123: 824-829.

27. Preiser JC, Schmartz D, van der Linden P et al. Interleukin-6 administration has no acute hemodynamic or hematologic effects in the dog. Cytokine 1991; 3 (1): 1-4.

28. Martin H, Olander B, Norman M. Reactive hyperemia and interleukin 6 , interleukin 8 , and tumor necrosis factor- $\alpha$ in the diagnosis of early-onset neonatal sepsis. Pediatrics 2001; 108 (4): E61.

29. Shin S, Kim Y, Jeong S, Hong S, Kim I, Lee W, Choi S. The therapeutic effect of human adult stem cells derived from adipose tissue in endotoxemic rat model. Int J Med Sci 2013; 10 (1): 8-18.

30. Yanay O, Bailey AL, Kernan K, Zimmerman JJ, Osborne WR. Effects of exendin-4, a glucagon like peptide-1 receptor agonist, on neutrophil count and inflammatory cytokines in a rat model of endotoxemia. J Inflamm Res 2015; 8: 129-135.

31. Böhrer H, Qiu F, Zimmermann T, Zhang Y et al. Role of NFkappaB in the mortality of sepsis. J Clin Invest 1997; 100 (5): 972-985.

32. Ikezoe T, Yang Y, Heber D, Taguchi H, Koeffler HP. PC-SPES: a potent inhibitor of nuclear factor-kappa B rescues mice from lipopolysaccharide- induced septic shock. Mol Pharmacol 2003; 64 (6): 1521-1529.

33. Sheehan M, Wong H, Hake PW, Zingarelli B. Parthenolide improves systemic hemodynamics and decreases tissue leukosequestration in rats with polymicrobial sepsis. Crit Care Med 2003; 31 (9): 2263-2270.

34. Howard M, Muchamuel T, Andrade S, Menon S. Interleukin 10 protects mice from lethal endotoxemia. J Exp Med 1993; 177: 1205-1208.

35. Bernard GR, Vincent JL, Laterre PF et al. Recombinant human protein C Worldwide Evaluation in Severe Sepsis (PROWESS) study group. Efficacy and safety of recombinant human activated protein $\mathrm{C}$ for severe sepsis. N Engl J Med 2001; 344 (10): 699-709.

36. Senftleben U. NF-kappaB in critical diseases: a bad guy? Intens Care Med 2003; 29 (11): 1873-1876. 